\title{
La edición de la Selección Samper Ortega de Literatura Colombiana Bibliotecas, editoriales e imprentas en la década de 1930
}

\section{Miguel Ángel Pineda Cupa}

Universidad Pedagógica Nacional, Colombia | miguelpineda93@gmail.com /

http://orcid.org/oooo-0oo1-9876-6052

\section{Resumen}

En este artículo se presentan los resultados de investigación sobre el proceso editorial que se llevó a cabo en la colección literaria Selección Samper Ortega de Literatura Colombiana. Se recopilaron diferentes textos nacionales (de varios géneros literarios) que ya existían y habían tenido un desarrollo editorial desde el siglo XIX; por esto, se analizan los aspectos principales que constituyeron este compendio de obras y que, en cierta medida, caracterizó la edición local a partir de 1930. Asimismo, se revisaron las relaciones personales entre el compilador encargado y los autores de la colección, la definición de labores con la Editorial Minerva de Bogotá, los contratos de edición y la propiedad literaria que cambiaron las interacciones entre las lógicas de lo impreso, lo divulgado, las bibliotecas y los patrimonios de las élites.

The publishing process of Selección Samper Ortega de Literatura Colombiana. Libraries, publishers and printers in the 19305

\begin{abstract}
This article presents the results of the research on the publishing process that took place in the Colombian series Selección Samper Ortega de Literatura Colombiana. Several national texts (of different literary genres) that already existed and had an editorial development since the nineteenth century were compiled. Thus, this article analyzes the main aspects that made this compendium of works and that, to a certain extent, characterized the local edition from 1930. Furthermore, the personal relations of the compiler with authors, the definition of editorial task with the Editorial Minerva of Bogotá, publishing contracts, literary property that changed the relation between the practice of printing, libraries and the heritage of elites were examined.
\end{abstract}

\section{Palabras clave}

Selección Samper Ortega de Literatura Colombiana Edición colombiana Literatura colombiana Bibliotecas

Colecciones literarias Imprentas

\section{Keywords}

Selección Samper Ortega de Literatura Colombiana Colombian publishing Colombian literature Libraries Literary series Printers 
1. Este artículo es resultado de la investigación realizada en 2016, en el marco de la beca de investigación Instituto Caro y Cuero en historia de la edición en Colombia, catálogos 1919-2014. El título del proyecto presentado fue "Una colección editorial para un país en busca de lectores.

La Selección Samper Ortega de Literatura Colombiana, 1928-1937"

2. El resultado fue Zoraya: una vida de amor y santidad, considerada una novela histórica, sobre la vida íntima de don José de Solís y Folch de Cardona, virrey de Santafé entre 1753 y 1761.

\section{Introducción ${ }^{1}$}

En 1927, el escritor y editor colombiano Daniel Samper Ortega (1895-1943) partió hacia España con un doble propósito: primero, buscar información para "escribir una novela histórica (de muy escasa circulación en Colombia)"² (Samper Ortega, 1937a: 11), y segundo, asistir como invitado de algunas universidades y entidades literarias, entre ellas la Universidad de Salamanca y la Unión Ibero-Americana, para ofrecer una serie de conferencias sobre la vida intelectual, artística y literaria de Colombia. Años después, en 1943, confesaría en entrevista con su amigo y familiar lejano Luis Enrique Osorio que había viajado a la península ibérica por la obsesión de escribir y radicarse en un país donde vivir de las letras era posible. En Sevilla aprendió el proceso de preservación y rastreo de archivos antiguos y vio en esos hallazgos la "codicia, el ansia de triunfos literarios en lo artístico y económico" (Samper Ortega, citado por Osorio, 1944: 7).

Tras su regreso a Colombia, Samper Ortega tenía en mente la creación de una empresa literaria que, según su propio concepto, hacía falta en el país y que era necesario prestar tal servicio a la nación, "difundiendo [el] pensamiento [colombiano] no solo dentro de su territorio sino en otras naciones" (Samper Ortega, 1937a, 9). Para crear una selección de textos era fundamental la revisión, elección y organización de la producción bibliográfica del país, que durante muchos años se preservó en diversas publicaciones periódicas, esto es, periódicos, suplementos, boletines y revistas. Así, surgió la Selección Samper Ortega de Literatura Colombiana, colección de cien volúmenes de obras colombianas, divididas en diez géneros (prosa literaria, cuento y novela, cuadros de costumbres, historia y leyendas, ciencias y educación, ensayo, periodismo, elocuencia, poesía y teatro) y que alcanzó tres ediciones y una planeación de cuarta edición consignada en manuscrito.

En ese sentido, en este artículo se analizan los antecedentes discursivos, contextuales y bibliográficos que dieron origen a la primera colección literaria de amplio número de volúmenes y autores nacionales, mediante la propuesta metodológica de Adams y Barker (2001) sobre el "campo coyuntural socioeconómico", en el que intervienen influencias y presiones en distintas dimensiones para la creación y existencia de un nuevo "documento bibliográfico" representado en una serie de textos colombianos. A diferencia de Darnton (1982) y su circuito de comunicaciones, Adams y Barker destacan la versatilidad teórica de estudiar una historia de las publicaciones más allá de las limitaciones que plantea la categoría "libro": de ahí que sea oportuno, además, entender los hechos que afectan los procesos de publicación, manufacturación, distribución, recepción y supervivencia, y superar la simple y desconectada relación con el contexto de las actuaciones que cada agente desempeña en las diversas etapas en el circuito de comunicaciones/producción/ historia del libro. Por esto, aquí se evidenciarán algunas influencias intelectuales y políticas, las presiones comerciales y el comportamiento social (Adams y Barker, 2001) como aspectos interconectados y cruciales para la consecución de la Selección Samper Ortega.

\section{“Tantear el terreno" para la estructuración de una colección de libros}

En 1928, Daniel Samper Ortega tenía claro que debía, primero, considerar dos puntos que le permitirían tantear el terreno de un plan de selección y publicación de obras nacionales: para reunir un amplio número de autores y textos colombianos del siglo XIX y de lo transcurrido del XX resultaría de gran interés consultar con diferentes eruditos y críticos no solo sus puntos de vista y guías -que resultarían 
útiles para seguir los antecedentes-, sino que podrían apoyar y financiar económicamente un trabajo en conjunto que representaría el mayor esfuerzo colectivo por las letras colombianas. A su regreso, Samper Ortega declara que no encontró suficiente apoyo en este sentido.

En cambio, sí contó con el apoyo de diversas amistades y contactos intelectuales cercanos que, según su criterio, tenían "buen gusto", espíritu de trabajo y constancia, que escribieron textos exclusivamente para la selección. A este asunto, en el que la iniciativa colectiva como idea primigenia era poca, se le sumaba que se requería una confianza económica que buscara a los socios indicados para ejecutar todos los procesos de publicación, entre estos, una imprenta comprometida y aliada.

Al principio, no fueron útiles las referencias, datos y visitas a la Biblioteca Nacional, de la cual fue director entre 1931 y 1938, pues antes de su gestión la encontró siempre con "todos los archivos revueltos, miles de tarjetas fuera de los índices, la mayoría de los casos equivocadas en la numeración; salas de libros revueltas [y] la prensa de todo el país formando un montón de varios metros cúbicos" (Samper Ortega, 1940: 6). Así que su experiencia de revisión de archivo adquirida en las bibliotecas españolas resultó necesaria para estructurar un plan que fue la clave de su labor como editor. Ante estas circunstancias, Samper consideró para tal plan

[I]eer metódicamente todo cuanto sea posible leer de lo que se ha escrito en Colombia; escoger, dentro de tales lecturas, sin antipatías ni preferencias por un autor o por un bando político; descartar con entereza cuanto nos parezca inferior, aun a riesgo de disgustar a los pontífices e incluir cuanto juzguemos digno de ser conocido, pese a las excomuniones de los diversos cenáculos no son faenas ni riesgos que gusten de tomar la mayoría de nuestros escritores consagrados (Samper Ortega, 1937a: 9).

Un primer ensayo de "selección" fue reunir en cuatro tomos los trabajos más importantes y útiles de José María Vergara y Vergara para un nuevo tiempo en el que los intereses de los lectores habían cambiado. Así, para Samper Ortega era necesario "escoger" textos fundamentales, en los que se evidenciara la autoría de Vergara y que dieran al lector una idea general de su estilo y sus géneros predilectos. Por ejemplo, durante la recopilación y edición Samper Ortega descartó el criterio de obras "completas" porque veía que "apenas [las] pueden consultar, y con trabajo, los eruditos", es decir, pensaba en otros lectores que no fueran exclusivamente eruditos (entre otros, escolares y universitarios). Con esto, en 1931 aparecerían las Obras escogidas de don José Maria Vergara y Vergara, publicadas gracias al apoyo de sus hijos Francisco José Vergara, Ana Vergara de Samper y Mercedes Vergara y Balcázar y bajo la dirección de Daniel Samper Ortega.

\section{Otros antecedentes de la Selección Samper Ortega}

Durante sus labores como profesor en el Gimnasio Moderno de Bogotá, Daniel Samper Ortega planeaba y estructuraba derroteros de temas que, a su juicio, eran aptos para niños en edades desde los ocho años hasta jóvenes de dieciocho. En su "Programa de castellano y literatura", para sexto año, dedicaba un párrafo completo a aquellas especificidades que debían tratarse con los alumnos sobre literatura colombiana. Allí se desglosaban, entre otros aspectos, los siguientes autores y periodos históricos de estudio: 
SEXTO AÑO/.

Literatura colombiana

[...] El periodismo en el Virreinato: Socorro Rodríguez, Caldas y sus colaboradores.Tertulias literarias de la colonia. Orígenes e historia del teatro en Colombia. - Los po[e]tas de la primera mitad del siglo XIX: Vargas Tejada, Fernández Madrid, José Eusebio Caro, Julio Arboleda, José Joaquín Ortiz, Gregorio Gutiérrez González.-El Mosaico y los Mosaicos: Vergara y Vergara, Carrasquilla, José María Samper, José Manuel Marroquín, Jorge Isaacs, Eugenio Díaz, los costumbristas y otros escritores de la época. - Los poetas Núñez y Fallon. - La escuela del Repertorio Colombiano: Martínez Silva, Camacho Roldán, Miguel Samper, Carlos Arturo Torres y otros.La novela en Colombia desde sus orígenes hasta el día.- Rafael Pombo.- José Asunción Silva.- Los prosistas Manuel Ancízar y Santiago Pérez Triana.- Los humanistas Caro, Cuervo y Suárez.- Poetas del fin de siglo: Julio Flórez, Diego Uribe, Roberto Mc. Douall y otros. - Escritoras colombianas. - Contemporáneos (Samper Ortega, 1928: f. 6).

Todos estos autores mencionados fueron incluidos en la Selección Samper Ortega. En cierta medida, esta planeación revela implícitamente una serie de autores, géneros y corrientes literarias colombianas que el profesor conocía para el desarrollo de sus clases o lecciones, pero queda en duda qué títulos, obras y ediciones nacionales podían usarse para propósitos académicos/educativos. A esta preocupación como docente, pero también como editor, Samper Ortega se dedicaría a solventarla; asunto del que se manifestaría en los siguientes términos:

Al regresar a Colombia en 1928 traía yo en mientes formar una colección de autores colombianos, no para el uso de los eruditos, a quienes temo y acato, sino para divulgar en el extranjero y entre los estudiantes de literatura las obras más salientes de nuestros escritores. Hacíase indispensable lanzarla pronto, y en condiciones económicas ventajosas a la mayoría (Samper Ortega, 1937a: 12).

$\mathrm{Al}$ respecto, hay un antecedente conceptual que vale la pena revisar, puesto que desde 1927 ya se venía hablando de "centenares" de autores colombianos para propósitos educativos. El escritor y docente Luis López de Mesa publicó un artículo titulado "Bibliotecas aldeanas", en el que explicaba las necesidades por las que pasaba el país en materia cultural y educativa, y resaltaba el imperativo de impulsar una nueva política encaminada al "esclarecimiento de la conciencia nacional" (López de Mesa, 1927). Para este autor, se requería de la administración del saber y las ideas contenidas en los libros, y aunque su costo y difícil ejecución serían reprochados, era fundamental aumentar "el nivel cultural de las masas populares de todo el país". Por ello, Samper tuvo en cuenta las palabras de López, especialmente la de construir una biblioteca de autores colombianos, pero requería una estructura clara.

Enrique Osorio a Samper Ortega en 1943, la esposa, María Amalia Gnecco Fallon intervino para precisar que para entonces ella se dedicaba a "catalogar la biblioteca de Daniel... cerca de ocho mil volúmenes" y había "oído leer novelas, obras de teatro, proyectos pedagógicos... He tenido en la casa imprenta, conferencias

financieras, huéspedes ilustres" (Gnecco, citado por Osorio, 1944:

9). Por estas razones, el hogar de Daniel Samper Ortega, a partir de su biblioteca, constituía un lugar trascendental para la iniciación y definición de distintos intereses en su afán de aportar al campo sociocultural local.

\section{Bibliotecas en busca de un orden}

El 1 de febrero de 1931 Daniel Samper Ortega fue nombrado director de la Biblioteca Nacional, por parte del presidente de la República, Enrique Olaya Herrera; hecho que constituyó un punto de quiebre en la historia cultural de país. Se renovaron todas las instancias internas de la institución que tenían que ver con nuevos métodos de catalogación, aumento de personal capacitado, instalación de los primeros elementos radiales y la construcción de un nuevo edificio, con mayor capacidad para organizar libros y disponer salas de lectura. Aquellos textos que Samper no encontraba en su biblioteca ${ }^{3}$ para su selección de textos nacionales, 
debía hallarlos en las de sus colegas o consultarlos en el repositorio bibliográfico más destacado, pero menos clasificado del país hasta entonces, la Biblioteca Nacional.

En sus primeros meses de gestión, Samper Ortega junto con once empleados se encargaron de iniciar la catalogación y ordenación del material disperso. Por esto, requirió personas con conocimientos para ejecutar, además, tareas de secretaría de la biblioteca y de la dirección, y archivadores en las distintas dependencias de la biblioteca y del Ministerio de Educación Nacional.

A partir de 1932, un grupo de escritores ingresó para ayudar a Daniel Samper Ortega en la organización de la entidad. Por ejemplo, designó al escritor Nicolás Bayona Posada como catalogador de 5.000 volúmenes en 1932; también llegó el historiador Eduardo Posada, quien se encargó de la clasificación del Archivo Histórico en ese mismo año; otro fue el escritor y poeta Luis María Mora, quien catalogó cerca de 1.000 títulos. Estos intelectuales, incluidos posteriormente en la Selección Samper Ortega, unos con obras, otros como autores de prólogos, reunían los saberes necesarios para las labores bibliotecarias y para la edición de la Selección.

A la secretaría de la dirección llegó, en 1931, una mujer que fue fundamental tanto para la organización de archivo de la biblioteca y de los papeles personales de Daniel Samper Ortega como para la de la selección, pues ella se encargó de la transcripción a máquina de los originales que se le enviaban a la Editorial Minerva para la consecución del trabajo del linotipista. Su nombre era Ana Josefa Bustos, conocida como "Pepa" Bustos. Se sabe de sus labores gracias a una fotografía que muestra a Daniel Samper Ortega y, detrás de él, un estante de su biblioteca, que contenía los cien volúmenes de la selección. En la parte inferior de la foto aparece la siguiente dedicatoria: "A los dedos de Pepa Bustos, de donde salieron las 18.000 páginas de esta Selección, y a su constante y leal amistad. / 1928-1937. Daniel Samper Ortega" (Rincón, 2010: 425, imagen 3).

Después de presentar la propuesta de la Selección a la Editorial Minerva y de suscribir un contrato que lo obligaba a entregar paulatinamente los originales de esta colección de textos, Samper Ortega retomó el trabajo de divisiones y ajustes:

la Casa Editorial Minerva, que desde hace años venía invirtiendo dinero en la 'Selección Samper Ortega de Literatura Colombiana', tenía que fijarme necesariamente un límite y me fijó el de cien volúmenes, cuyo promedio no debía exceder de 180 páginas (Samper Ortega, 1937a: 19).

Para esta parte, se puede revisar un caso importante y definitivo en el que las relaciones autorales y editoriales estuvieron en constante tensión. Sucedió con la sección de "Periodismo", en la que Samper Ortega ya había acordado desde 1931 con el historiador Gustavo Otero Muñoz (1894-1957) que este abriría ese conjunto de textos. La relación entre estos dos intelectuales se remonta quizá a la época en que Samper le solicitó títulos para Santafé y Bogotá, además de su trabajo en conjunto para las Obras escogidas de Vergara y Vergara, en las cuales Otero se había encargado de los apéndices y las notas de Historia de la literatura en Nueva Granada. Ambos perfiles, que compartían el propósito de búsquedas bibliográficas exhaustivas y fuentes del pasado de la historia cultural nacional, escribían semanalmente en los principales diarios de Colombia sobre asuntos literarios con columnas cargadas de referencias de múltiples obras y trabajos de intelectuales de su generación o de años anteriores ${ }^{4}$. A través de correspondencia (quizás el autor con quien más dialogó Daniel Samper para la selección) las dos partes se dedicarían a la edición del volumen 61 de la Selección, titulado Historia del periodismo en Colombia.
4. Por ejemplo, Otero escribió sobre bibliografía de la historia del periodismo en Colombia (Santafé y Bogotá, vol. 3, n. ${ }^{\circ} 35$, nov. 1925), sobre la literatura colonial y la popular de Colombia (Santafé y Bogotá, vol. 6, n. ${ }^{\circ} 71$, nov. 1928), acerca de Guillermo Valencia, su personalidad y su obra (El Gráfico, vol. 19, n. ${ }^{\circ} 950$, oct. 1929), o sobre el costumbrismo en Colombia (Santafé y Bogotá, vol. 7, n. ${ }^{\circ} 80$, sep. 1930). Asimismo, el escritor Guillermo Hernández de Alba (1961: 176) recordó a Samper Ortega, colega suyo en la Biblioteca Nacional, por "los comentos artísticos y bibliográficos con que desde sus mocedades ilustraba las páginas de los principales periódicos y revistas bogotanos, dieron paso al ensayo madurado al amor de la rica biblioteca [personal] heredada de sus ilustres tíos José María Samper y Soledad Acosta de Samper" (p. 176). 
A partir de finales de 1931, Otero, quien se encontraba en la Secretaría de Gobierno de Santander (Bucaramanga), se dedicó a la redacción de este libro en los términos de una síntesis crítica de la historia del periodismo en Colombia. Así lo consignó en una carta enviada a Samper el 1 de diciembre de 1931:

[...] Ultimamente he consagrado mis ocios a reponerte la síntesis crítica de la Historia del periodismo que quedé comprometido a escribirte para tu colección de Autores nacionales. Dime si todavía es tiempo para seguir con el trabajo y enviarte lo que ya vaya produciendo en dos o cuatro entregas, conforme lo hicimos con los Apéndices. Es una obra muy compendiada, en que casi prescindo de la parte bibliográfica, y atiendo de preferencia a dar una impresión de conjunto, para hacer más amena su lectura. Te abraza cordialmente, Gustavo (Otero Muñoz, 1931: archivador 3: f. 2).

Los tiempos y el número de entregas fueron fundamentales para que en menos de siete meses este libro estuviera listo, pues la presión que ejercía Samper a lo largo de la correspondencia haría que Otero enviara mensualmente de a una o dos partes. Solo hasta el 28 de enero de 1932 llegó la primera parte de Historia del periodismo en Colombia, que constaba de once páginas (Otero Muñoz, 1932a), pero sin saber realmente cuántos capítulos se desglosaban en ellas, pues los originales no se conservan en el archivo particular de Samper Ortega. Su compromiso o labor, como se puede ver, se ejecutaba primero como un manuscrito que había que pasar mecanografiado para ser enviado semanalmente, hasta completar cincuenta páginas dependiendo de la solicitud de Otero para calcular extensión con respecto a las pruebas impresas en pliegos. A la par, Otero trabajaba en su propio proyecto editorial, anunciado en la carta de 1932:

Aquí voy a hacer algo semejante a lo tuyo, lanzando una "Biblioteca Santander", formada de escritores literarios e históricos de autores santandereanos, cuyo primer volumen contendrá algo de la obra poética de Martínez Mutis, y que aparecerá la semana entrante. Cada mes echaremos uno, y allá te irán llegando (Otero Muñoz, 1932b: archivador 1, f. 1).

En efecto, esta colección literaria departamental, una de las primeras en el país, empezó en 1932 con el primer volumen titulado Mármol, de Aurelio Martínez Mutis, y en adelante publicó los trabajos de su hermano Alfonso Otero Muñoz, Carlos Martínez Silva, Enrique Otero D'Costa, Simón Harker o Florentino Vezga.

Entre 1930 a 1936, Samper contaría con Otero no solo para lo anteriormente visto, sino para consultar referencias en todos los campos en los que pretendió dividir la literatura colombiana en su selección, pues Otero "pos[eía] una bien nutrida biblioteca, especialmente rica en revistas colombianas" (Samper Ortega, citado por Otero Muñoz, 1937: xiii).

\section{Labores simultáneas para definir formas: la Editorial Minerva y la Selección Samper Ortega}

Desde 1932 Daniel Samper Ortega impulsó la construcción de un censo cultural y literario que relacionara nombres y cantidades de bibliotecas, librerías, academias e imprentas en los diferentes departamentos del país. Años más tarde, se elaboró otra lista, denominada "Relación de imprentas y tipografías existentes en la República de Colombia, 1935", que se encuentra en el Archivo Histórico de la Biblioteca Nacional y publicada en la revista Sociedad y Economía no. 6, en abril de 2004 (Silva, 2004). En esta última se encontraba el nombre de Tipografía 
Minerva, de la que era propietario o encargado Juan Antonio Rodríguez, uno de los impresores más expertos de la capital colombiana y que incluso trabajó en la Imprenta Nacional de Colombia.

Esta tipografía, al parecer, surgió con el propósito de prestar algunos servicios a estudiantes que hacían sus trabajos de grado para optar por títulos profesionales universitarios. También fue fundamental para la impresión de publicaciones periódicas, como Bogotá Cómico: semanario ilustrado (1917), El Santafereño (1919), El Combate: interdiario conservador (1919) o Revista del Instituto Técnico Central (c. 1919-1922). Sobre el cambio de registro de "Tipografía" a "Editorial Minerva S. A.", en el archivo de la Cámara de Comercio de Bogotá se encontraron al menos siete registros que relacionan documentos oficiales de esta editorial, sus actividades notariales y los cargos administrativos que varias personas asumieron a lo largo de su constitución como sociedad anónima. Parece que su evolución a esta modalidad de "sociedad anónima" solo se daría en 1930; antes de ese año, posiblemente, convivían ambas referencias de un mismo negocio y propietario, es decir, tipografía y editorial. Dicha editorial y sus gerentes conformaron una sociedad que quedó legalizada a partir de un contrato de sociedad tramitado el 23 de junio de $1930^{5}$.

Con esto, es posible entender por qué Samper sometió a consideración de una sociedad anónima, después de tres meses de constituida, el patrocinio de una selección de textos que requerían elevados costos para cientos de ejemplares. De entrada, entonces, se puede afirmar que la Selección Samper Ortega fue realizada con el apoyo de múltiples accionistas y aportantes que asumieron el riesgo de impulsar nuevos libros bajo el concepto de una "selección". Esta sociedad anónima podría constituir un ejemplo primario y fundamental para un ejercicio y un ámbito editorial moderno, al transformarse en una sociedad con un capital arraigado y un proyecto editorial ambicioso. Con respecto a los socios, aparte de los registros, la amplia correspondencia que mantuvo Samper Ortega con la Editorial Minerva relaciona al menos seis socios o colaboradores de la empresa durante la década de 1930. Entre ellos, se encontraba Francisco José Urrutia Holguín ${ }^{6}$, abogado de profesión, quien nació en Quito en 1910, hijo del jurista y diplomático Francisco José Urrutia Olano. Para 1935, la Editorial Minerva atravesaba por alguna dificultad económica, probablemente desde hacía varios meses o quizás años, que le impedía proseguir con constancia la impresión y distribución de la Selección Samper Ortega, ya que empezó a imprimirse en 1932, tendría una regularidad inestable y se publicaría completa en 1936. Urrutia, por entonces, viajaba constantemente a Estados Unidos para traer insumos para la editorial colombiana, como se constata en la correspondencia alojada en el Archivo Histórico de la Biblioteca Nacional (Samper Ortega, 1935).

Otro de los que se mencionan en la correspondencia que Daniel Samper Ortega mantuvo con esta sociedad es Vicente Rubio Marroquín, de quien se sabe que fue hijo de Luis Rubio Saiz y de María Josefa Marroquín Osorio -hija del expresidente José Manuel Marroquín y hermana del escritor Lorenzo Marroquín-. Rubio fungía como secretario de la editorial y manejaba el contacto con los clientes a quienes anunciaba o mantenía al tanto de los procesos de edición de los libros que se hacían y de los asuntos financieros. Para comprobar las funciones cumplidas por Rubio, basta con citar la carta que el secretario de la editorial envió el 19 de enero de 1933 a Samper, a quien le asignaba el cargo de revisor fiscal de la empresa para el nuevo periodo que principia el 1 de febrero de ese año (Rubio Marroquín,1933). La sociedad anónima de accionistas que conformaban la Editorial Minerva designaba a Samper el cargo de vigilancia y rendición de cuentas para ese año, un asunto que refleja la multiplicidad de roles y cargos ejercidos en el interior de la firma: accionistas-inversionistas, editores, gerentes, secretarios, compiladores, autores.
5. Véase Cámara de Comercio de Bogotá (CCB), Editorial Minerva S.A. NO E Y R, n. ${ }^{\circ}$ de registro 6822 , f. 1. Tres de los siete registros hallados para esta investigación fueron tramitados entre 1930 y 1938, los demás fueron producidos en los primeros años de la década de 1940 y uno cerca de 1960 , que parece liquidar la sociedad definitivamente. Estos cambios obedecen a lo que Chartier denomina "transformaciones mismas del capitalismo editorial [que] provocaron reagrupamientos" (2000: 37).

6. Su cargo como gerente de la Editorial Minerva también puede constatarse por una carta que Urrutia le envía al escritor José Antonio Osorio Lizarazo, en agosto de 1930, en la que se comentan algunos detalles de la publicación y distribución de la obra La casa de vecindad. Esta correspondencia, que se mantiene varios meses en adelante, relaciona asuntos como el modelo de suscripción con respecto al número de ejemplares, propaganda del libro, envío de pruebas impresas para corrección e incluso se menciona un viaje de Urrutia a Europa, lo que confirma las funciones específicas de este accionista y gerente de la editorial (Vanderhuck, 2012: 69 y ss.). 
7. Sin duda, el linotipo revolucionaría la forma de hacer diarios, revistas y libros por su rapidez, al reducir los procesos y tiempos. Para Chartier (200o), el tránsito del siglo XIX al XX en Europa representa un época de "aumento de tiradas, crecimiento de producción impresa, multiplicación de publicaciones periódicas" que contribuyeron a una mutación técnica asociada a una superproducción sin precedentes. Según el exdirector de la Imprenta Nacional de Colombia, Tarciso Higuera, los primeros linotipos Ilegaron a Colombia en 1911, y de ahí que aunque para Europa haya significado una crisis económica para editores, libreros e impresores, en el caso colombiano pudo haber representado una nueva época tras el auge de las sociedades literarias que se venían desarrollando desde la segunda mitad del siglo XIX y con ellas, nuevos grupos de lectores (mujeres y obreros) y nuevas técnicas de impresión e ilustración (fotograbados y litografías) (Vasco Acosta, 2018).

8. Auque Samper Ortega sea considerado el editor-compilador de la Selección, Pedro Escobar también era considerado en los términos de "editor de la Selección Samper Ortega de Literatura Colombiana", según lo consigna literalmente Samper en esta carta. En ese sentido, convivían distintas concepciones fragmentadas, dispersas y dinámicas de este rol desempeñado durante la década de 1930 en Colombia, una labor, en términos de Chartier (2000: 37) "de naturaleza intelectual y comercial que apunta a buscar textos, a descubrir autores, a vincularlos con la casa editora, a controlar el proceso que va desde la impresión hasta su difusión. El editor puede poseer una imprenta, pero no es necesario

$y$, en todo caso, no es eso lo que fundamentalmente lo define".
Sin duda, con el gerente que más tuvo cercanía Daniel Samper Ortega fue Pedro Ignacio Escobar Umaña, abogado no graduado de la Universidad Externado de Colombia, nacido el 27 de septiembre de 1904 y fallecido el 3 de septiembre de 1959. Pedro Escobar realizó sus estudios escolares en el Gimnasio Moderno en la segunda década del siglo XX. El 14 de diciembre de 1935 se casó con Rosa Patiño Gaitán quien, según registros de la Cámara de Comercio de Bogotá, era también accionista de la editorial y representada por su esposo en las asambleas generales. Escobar fue uno de los primeros gerentes de la Editorial Minerva, en palabras de Samper, su mayor accionista y, quizás, la primera persona con quien Juan Antonio Rodríguez estableció un contacto cercano para ampliar el negocio editorial. Así, Escobar llegó a ser prácticamente dueño del taller de imprenta en 1937, según correspondencia que reposa en el archivo de Samper del Gimnasio Moderno de Bogotá. Otro colaborador y empleado de la editorial fue Guillermo Escobar Umaña, hermano de Pedro Ignacio, aunque no se ha podido determinar su rol dentro en esta. También, uno de los socios gerentes de esta compañía fue Eduardo Suescún, y un colaborador o secretario no del todo identificado, Alfonso Robledo Mejía.

La Tipografía Minerva registraba ubicación, según un aviso publicitario de Santafé y Bogotá de 1923, en la carrera $6^{a}$ n. ${ }^{\circ} 978$, nomenclatura que ubicaba a estos talleres cerca del sector de Las Cruces, donde se mantendría hasta 1930, como se sabe gracias al Directorio comercial e industrial del país (Ministerio de Industrias, 1930: 183), que la registraba como "Editorial Minerva", en vez de "Tipografía Minerva". Para 1932, los talleres de la Editorial Minerva S. A. se ubicaban en la carrera 6a \# 3-23 y los despachos de la gerencia estaban ubicadas en el edificio del Banco Central Hipotecario, oficina 701, que en 1936 cambió a la calle 18 \# 5-34.

En cuanto a los elementos de imprenta que Editorial Minerva había importado desde hace varios años, en una carta que Daniel Samper Ortega envió al editor manizaleño Arturo Zapata especificaba la existencia de las maquinarias que habían funcionado para imprimir libros, como la Selección Samper Ortega de Literatura Colombiana. En la misiva, Samper relacionaba lo siguiente:

los elementos que tiene aquí la Minerva que, a grandes rasgos y hasta donde yo recuerdo, son más o menos los siguientes: monotipo, linotipo 7,3 máquinas rápidas grandes, 2 prensas, una formidable cortadora, plegadora, cosedoras, fuentes diversas en gran cantidad y variedad y una buena existencia de metal (Samper Ortega, 1937b: f. 1$)^{8}$

Además del conocimiento del trabajo editorial e impresor, Samper supo estrechar relaciones contractuales con la Editorial Minerva. Entre los papeles del archivo privado de Daniel Samper Ortega se conserva una copia, que como su título señala, es un "proyecto de contrato" en el que se estipularon ciertos compromisos laborales y económicos que muestran cómo la distribución de responsabilidades y ganancias determinaron el buen funcionamiento de la empresa conjunta. Este proyecto, que aunque no es el contrato definitivo, parece que fue efectuado como un balance entre lo acordado y lo realizado desde hacía seis años, pues se relaciona información de la segunda y la tercera edición que estuvieron listas y completas entre 1936 y 1937. El plan contenía resumidamente lo siguiente:

\section{PROYECTO DE CONTRATO}

Pedro Ignacio Escobar y Daniel Samper Ortega, ambos casados, mayores de edad y vecinos de esta ciudad, hacemos constar que con fecha 16 de septiembre de 1930 el primero en su carácter de Gerente de la Editorial Minerva, S.A. y el segundo en su propio nombre celebraron un contrato mediante el cual Samper Ortega 
se obligó a entregar a la Editorial Minerva S.A. originales escogidos de autores nacionales con las respectivas biografías y libres de derechos de autor, para que la citada empresa los imprimiese en cien volúmenes de que debería constar una colección o biblioteca literaria que se denominaría SELECCIÓN SAMPER ORTEGA DE LITERATURA COLOMBIANA. Que se acordó repartir las utilidades por mitad entre la empresa capitalista y el autor de la SELECCIÓN, que éste conservaría la propiedad literaria y que recibiría cien colecciones para propaganda y compra de derechos de autor. Que oportunamente Samper entregó todos los originales, prólogos y biografías, y que Pedro Ignacio Escobar, quien sustituyó a la Editorial Minerva S.A. en las obligaciones y derechos de la empresa con relación a este negocio, [...] imprimió por su cuenta dos ediciones completas de la mencionada SELECCIÓN SAMPER ORTEGA DE LITERATURA COLOMBIANA, ediciones que vienen siendo la segunda y la tercera y que fueron destinadas, aquella al Ministerio de Educación Nacional, y ésta a ser vendida, previo acuerdo con Samper Ortega (Samper Ortega, s.f., carpeta "Contratos literarios": f. 1).

El primer aspecto a destacar de este supuesto contrato es que se refiere insistentemente en la segunda edición (oficial, en formato cartilla de $13 \times 18,7 \mathrm{~cm}$, Biblioteca Aldeana de Colombia, Ministerio de Educación Nacional) y de la tercera edición (comercial, 12 $\times 16,7 \mathrm{~cm}$ ). En 1935 estas dos ediciones tuvieron que impulsarse pues por presión del Ministerio había que cumplir un plazo estipulado para su realización, deteniendo la producción de la primera (edición comercial, libro de bolsillo, $8,5 \times 12,5 \mathrm{~cm})^{2}$. Esto quiere decir que la primera solo existió gracias a lo definido en la segunda y tercera, muestra de un hecho determinante en las formas y tiempos de publicación, debido a una política estatal en la que incluso el "Estado-editor" determinaba asuntos formales de su edición. De ahí que la existencia de un contrato primigenio de 1930 de la primera edición no haya considerado totalmente o no haya muestras claras en el archivo particular de Samper Ortega, pues debió ser reformulado a mediados de década.

\section{El contrato entre la Editorial Minerva y el Gobierno nacional en 1935}

La figura de Luis López de Mesa, años antes en el acuerdo de una edición oficial de textos literarios colombianos para bibliotecas, canjes y sectores culturales e intelectuales, es importante puesto que sentó las pautas que influyeron en la Selección Samper Ortega de Literatura Colombiana. El desarrollo de una cultura aldeana dependió, en gran parte, del uso del libro para guiar y abanderar reformas educativas que incluyeran en las discursividades y en las prácticas al "pueblo".

Para dicha transformación se requería la materialidad y el contenido del libro, era necesario pensar y preguntarse qué y cómo se exigían ciertos elementos compositivos que unificaran propósitos con miras a construir un concepto sobre lo cultural y lo popular en el país, a partir de una recapitulación del pasado. Por ello, López de Mesa apuntaba a un centenar de obras afamadas y ya realizadas, ideas que también siguió Samper con propósitos similares e invariables en el tiempo de "prestar un servicio a la patria".

Aceptados los puntos comunes y compatibles las iniciativas entre Samper, Editorial Minerva y López de Mesa, el contrato estipulaba que se imprimieran 2.000 colecciones de la Selección Samper Ortega. Además,

para cartillas de la serie literaria: cada colección se [componía] de cien (100) cartillas, con un promedio aproximado de ciento ochenta páginas por cartilla, con excepción de diez cartillas máximum, que [tendrían] menos de las ciento sesenta páginas.
9. Para Chartier (200o), el formato de bolsillo multiplica "las lecturas de quienes ya eran lectores", y en ese sentido, según la correspondencia revisada para esta investigación, los primeros beneficiados en este proceso de divulgación y popularización de la literatura colombiana fueron lectores de círculos intelectuales y políticos nacionales que aplaudieron y comentaron dicha selección a lo largo de los años, principalmente desde 1936 a 1938. Asimismo, los títulos seleccionados para la colección literaria de Samper Ortega forman parte de un "corpus clásico de textos “legítimos”" que ven una nueva forma y un nuevo periodo de circulación y uso con la aparición del libro de bolsillo. En conclusión, para Chartier, este formato de publicación y lectura tiene la facultad de llegar a ser "un objeto de colección” (2000: 69). 
Segunda. El plazo para la entrega total de la obra es de ocho (8) meses, que empezarán a contarse desde el día en que se haga al Contratista la entrega del papel y la cartulina necesarios para la obra. Si el Gobierno se demorare más de un mes en hacer los pagos de que trata la cláusula cuarta de este contrato, ésta demora se acumulará al plazo estipulado.

Tercera. El Gobierno se compromete a suministrar el papel y la cartulina para la portada en un tamaño de ochenta por ciento catorce (80 por 114), para hacer la edición en un veinteavo, en cantidad suficiente.

Cuarta. El Gobierno pagará al Contratista la cantidad de treinta mil pesos $(\$ 30,000)$ como valor total de la edición de las dos mil $(2,000)$ colecciones, de a cien $(100)$ cartillas [...]. (Ministerio de Educación Nacional, Diario Oficial, 1935: 531-532).

De este contrato se destaca la cantidad de ejemplares que constituían esas 2000 colecciones: 200000 ejemplares, una cantidad que debía estar lista en ocho meses y que los linotipos, las dos prensas, una cortadora, plegadora, cosedoras, diferentes fuentes y el metal no alcanzaban para esa gran cantidad. La Editorial Minerva, a partir de 1936, contó con el apoyo de las imprentas Óptima, Renacimiento, Diario Nacional, ABC y Selecta, que fueron subcontratadas para lograr la meta de las 2000 colecciones. Muy seguramente se acordaron términos comunes en cuanto a aspectos editoriales y económicos para lograr la unanimidad y homogeneidad para la presentación y asuntos físicos de cada libro que compone la selección. Sin embargo, la Editorial Minerva tuvo conflictos con la Editorial $\mathrm{ABC}$ por razones contractuales, en las que una asignaba un dinero a cambio o compromiso de que la otra entregara un número de ejemplares de la selección, como se constata en correspondencia alojada en el Archivo Histórico de la Biblioteca Nacional (Suescún, 1937).

Este aspecto es importante porque define las condiciones del trabajo industrial editorial para que las ediciones resultaran homogéneas, iniciativa que quizás planteó la Editorial Minerva como medida preventiva para sacar ediciones íntegras desde su formalidad y contenido. No obstante, en esta investigación se revisó la tercera edición, y al menos 12 volúmenes de los 100 cambiaron su presentación en portadas (familias, fuentes y tamaños tipográficos distintos a la mayoría, información invertida en lomos y sin usos de orlas o decorativos). Con esto, las diferencias entre editoriales e imprentas iban más allá de cuestiones monetarias y cantidades del producto; también se notó en la composición general de algunos libros.

\section{Características de la Selección Samper Ortega}

\section{La segunda edición}

Es preciso anotar que la idea primigenia de Samper Ortega de libros en formato libro de bolsillo había adquirido una transformación discursiva que ponía en otros términos las referencias a la producción de libros. Ya no se trataba de libros pequeños sino de "cartillas" que requerían un aumento de formato, de tamaño tipográfico, resistencia y perdurabilidad en papeles e incluso considerar un empastado. Quien tenía las ideas claras sobre libros en formato amplio era Luis López de Mesa que, como se ha dicho, desde 1927 comentaba detalles necesarios para pensar una edición de libros a ser distribuidos en escuelas y bibliotecas rurales:

Quisiera, sin embargo, dejar un margen amplísimo para iniciar ediciones de nítida impresión, tipo grande y encuadernación en pasta española, que tengan mayor duración y no estropeen la vista de los lectores, como ocurre frecuentemente con casi todas las ediciones baratas, dentro y fuera de Colombia (López de Mesa, 1927). 
Estas pautas por supuesto suponían unas necesidades y capacidades del lector de otros contextos. Según López de Mesa era importante ponderar una impresión de alta o gran calidad (en cuanto a al uso oportuno de tintas y su aplicación en papeles adecuados), la implementación de materiales para la perdurable conservación que no se cumplía en la mayoría de las ediciones colombianas, y además, entendía a su parecer que los libros colombianos eran elaborados en tamaños tipográficos de pequeñas dimensiones que afectaban la condición visual de los lectores.

La Selección Samper Ortega se empezó a imprimir en 1932 en un papel liviano, de gramaje inferior a 70, cercano al tipo de papel conocido como "gaceta". Los pliegos de 80 volúmenes de $8,5 \times 12,5 \mathrm{~cm}$ estaban listos a principios de 1935 , y en ello Samper haría constante énfasis al ser interrogado. El contrato estatal efectivamente truncó la finalización de esa primera edición y la que se llevó el protagonismo y la originalidad o esencia de la idea fue toda la conceptualización que se dio en torno a la "Biblioteca Aldeana de Colombia", la del Ministerio de Educación Nacional. En adición, Samper fue acusado de haber intervenido en los programas de educación secundaria para inscribir su nombre en las nuevas políticas de esa cartera. En diferentes documentos, Samper insistía en que la selección había existido antes de esas nuevas implementaciones, y que había sido el ministerio el que había hecho la negociación con la editorial, no con él. Las críticas también tenían que ver con que el Ministerio de Educación había conferido "a un determinado ciudadano la tarea de señalar los mejores autores del país" (Silva, 2012).

\section{La tercera edición}

Para finales de 1936 se habían repartido cerca 1300 colecciones de las 2000, lo que dejaba un saldo reducido que no alcanzaría a cubrir los miles de solicitudes que llegaron, con insistencia incluso hasta 1938, al Ministerio de Educación y a la Biblioteca Nacional, como se puede ver en los formatos de canjes y correspondencia en los tomos del Archivo Histórico de la biblioteca. Un grupo cercano a 350 bibliotecas aldeanas aún no adquiría las colecciones, además de particulares, colegios, ministerios, funcionarios y prensa, y por ello fue necesaria la compra de otros cientos de colecciones por parte del ministerio para continuar con los despachos pendientes. De ahí que la existencia de una tercera edición se hiciera en simultáneo con la segunda y de esta tercera se tomaran algunos ejemplares de la totalidad que sería vendida en librerías como la Librería Colombiana de Camacho Roldán y en contacto directo con las oficinas de la Editorial Minerva, a la que llegaban miles de cartas remitidas del Ministerio y de la Biblioteca con la petición de distintos lugares del país y del mundo. Así, se puede comprender que la casa editora previó una creciente demanda de la que sacó provecho con la venta de una edición comercial.

Con esto, la Editorial Minerva, a través de su mayor accionista, Pedro Ignacio Escobar, invirtió en una tercera edición que empezó a componerse en 1935, que redujo el formato de las cartillas a un $12 \times 16,7 \mathrm{~cm}$, importó un papel de mejor calidad, eliminó elementos gráficos o iconográficos en portadas, y redujo el gramaje de la cartulina de las cubiertas lisas, sin imitación de otros materiales, de color semejante al naranja rosado y otras en azul claro. Esta edición no tuvo ajustes o modificaciones de contenido, pues fue una copia idéntica de la segunda edición y tan solo cambió su presentación.

\section{La primera edición: reanudación y última edición impresa en 1937}

En 1930 se había determinado que la primera edición en tamaño bolsillo debía conservar un formato común de $8,5 \times 12,5 \mathrm{~cm}$, con pliegos de papel semejantes al gaceta de tamaño $34,8 \times 25 \mathrm{~cm}$ y agruparía entre 15 y 20 cuadernillos cosidos. 
Samper insistió siempre que su empresa privada ya tenía 80 volúmenes en pliegos, sin encuadernar, hasta 1935 . Sin embargo, la aseveración no es clara, porque es importante preguntarse cuántos ejemplares de esos 80 aparecieron antes del contrato con el gobierno de Alfonso López Pumarejo, qué volúmenes y en qué orden. Algunas cartas en su archivo privado dan algunas pistas del proceso que desde 1930 había iniciado con la editorial bajo contrato. Por ejemplo, el 25 de abril de 1934 Daniel Samper Ortega escribió una carta a su colega Camilo Carrizosa, diplomático colombiano en Buenos Aires, en la que comentaba los pormenores de su avanzada y pequeña selección:

[...] quiero contarle que desde hace cerca de ocho años estoy empeñado en sacar a luz una colección de literatura colombiana. Para formar la cual he seguido el consejo que usted me da en su carta o sea el de recorrer uno a uno los periódicos en donde quedó la producción intelectual de nuestros abuelos; porque la "tomificación" es moda bastante moderna. Esta colección que sera [sic] una de las más útiles actividades que me sea dable ofrecer a mi país, estará terminada, si la guerra no se desencadena y la situación se compone, para fines de 1934 o a principios de 1935. Consta de cien volúmenes, en los cuales figura todo lo que ha tenido verdadero valor dentro de nuestro movimiento intelectual; creo que será una sorpresa no sólamente para Colombia sino para la América Latina [...]. De ella llevo jasómbrese usted! 72 tomos ya impresos. Pero no he querido decir una palabra ni la diré hasta que no esté completo el centenar, porque en Colombia le tenemos desconfianza, y con razón, a las publicaciones por entregas (Samper Ortega, 1934).

En esta carta aparece otro no menor importante antecedente familiar que, aunque discursivo, muestra los orígenes cercanos del propósito de reeditar la producción intelectual colombiana de años pasados. Samper atribuía un carácter moderno al ejercicio de pensar en volúmenes aparte, organizados por números, periodos y temáticas, asunto que sucedió con mayor insistencia en los primeros años del siglo XX y del cual él buscaba ser parte. El oficio editorial colombiano "moderno" estaba definido, entonces, por la creación de colecciones o selecciones que requerían de iniciativas privadas, asocio con inversionistas capitalistas y la independencia o separación de medios de circulación periódica y de sus complejos sistemas de suscripción. Se menciona un acontecimiento que para abril de 1934 no había concluido: el conflicto colombo-peruano. Esta problemática política y económica, que para el 1 de septiembre de 1932 había reanudado las diferencias y fuertes enfrentamientos con la toma de Leticia por parte de miembros del ejército peruano, solo finalizó el 24 de mayo de 1934, un mes después del envío de la carta a Carrizosa, fecha en la que se firmaba el protocolo de Río de Janeiro y en el que se acordó la paz definitiva y aspectos limítrofes entre ambas naciones.

\section{Los índices de la Selección Samper de Literatura Colombiana}

La idea de publicar un último volumen, que sería el 101 (Índices), se dio por la misma época en que se iniciaban las labores de ajustes de la primera edición. Con la necesidad de justificar las críticas que circulaban en la prensa, sobre la compilación hecha por Samper, así como las múltiples erratas que por correspondencia llegaban a su despacho, Daniel Samper ideó un volumen que se construyó a partir de los "buenos" y "positivos" conceptos que las instituciones y muchas voces oficiales e intelectuales emitieron al respecto. Además, buscó relatar gran parte del proceso editorial completo que llevó a cabo durante nueve años y al final estructuraría en diferentes tipos de índices todo el contenido de los cien volúmenes de su obra. 
Quizás la particularidad de este libro radica en que es una de las primeras memorias editadas de un compilador colombiano en el que se siente la necesidad de explicar los pormenores por los que atravesó para la edificación, volumen por volumen y sección por sección. La principal razón por la que algunas palabras se compusieron mal, algunas portadillas se confundieron con otros textos o volúmenes o se omitieron algunas líneas de texto, se debe a su carencia en el proceso de revisión de pruebas "en momentos en que yo me encontraba terriblemente recargado de trabajo en la Biblioteca Nacional". Y añadió:

\begin{abstract}
Me resultaba pues, de todo punto imposible corregir personalmente las pruebas y tuve que resignarme a que lo hiciesen individuos que nos fueron recomendados a la imprenta y a mí como prácticos en el oficio y como personas eruditas y meticulosas. Pero como la casa editora trabajaba conminada con una fuerte multa si al vencimiento del plazo no había entregado el trabajo, la edición se llevó a término dentro de una vorágine en que diversos correctores y diversas editoriales se afanaban ${ }^{10}$, sujetos, además, al moderno suplicio del linotipo, máquina admirable para ganar tiempo, pero que tiene el inconveniente de que en cada lingote o renglón que se corrige es fácil, si no se cotejan repetidas veces los moldes, cometer nuevos errores (Samper Ortega, 1937a: 25-26).
\end{abstract}

Como Samper y la editorial no contaban con el tiempo suficiente durante 1936 para cotejar las pruebas con originales, o de asistir al taller para hacer los últimos ajustes, diversas erratas se habían impreso a lo largo de los cien volúmenes. Parece también que los correctores no fueron los más idóneos para ejecutar tal labor, prueba entonces de que el escenario editorial colombiano aún no contaba con personas oficiosas en el tema y que las casas editoras, más que todo, se valían del mismo autor para que él hiciera la comprobación con los originales. La ausencia de Samper en este punto del proceso (lo que pareció justificar que de él no provenía la responsabilidad de cómo quedaron los volúmenes de las distintas ediciones de la selección) generó errores principalmente en "letras cambiadas o al revés y algún lingote derrumbado". Un tipo de errata consistió en que, por ejemplo, dependiendo del tipo de fuente o familia tipográfica, una "I" (i en caja alta) podía ser confundida con una "l" (ele en caja abaja) o con un " 1 " (uno).

\section{Una cuarta edición planeada}

Hacia finales de 1937, Daniel Samper Ortega estaba conformando listas manuscritas y mecanografiadas de nombres de autores y textos colombianos; sin embargo, la prensa le reclamaba la no inclusión de otras plumas de renombre en su selección. A su vez, no comenzaría la realización de unos originales de erratas después de publicado el volumen de Índices porque, como se ve en su extensa correspondencia, vio más práctico comunicarse con los autores y prologuistas vivos de la selección para solicitar la revisión, aprobación de lo publicado, y si había modificaciones (en cuanto a contenido y yerros tipográficos) que fueran ellos mismos los que decidieran una forma final de sus textos y de los que pertenecían a los fallecidos. Por ello consideró más pertinente una cuarta edición que comprometiera y vinculara directamente a los miembros y colaboradores de la selección y no fuera una tarea de uno solo. Con esta iniciativa, Samper empezó a trabajar en una última edición que quedó estructurada en papeles y notas personales, pues se fundamentó en los consejos de los demás y no en el criterio personal. Tal vez esta fue la razón por la que Samper decidió someter a evaluación colectiva su labor compilativa, y ante las constantes quejas, pensó en una edición "de o por los autores" y miembros de la intelectualidad colombiana que en una particular o individual.
10. De ahí que para reconstruir un estudio detallado sobre las distintas decisiones e intervenciones que dieron forma impresa a la Selección Samper Ortega se deben tener en cuenta "los hábitos de los obreros que [la] compusieron para transformar[la] en [libros impresos]" (Chartier, 2000: 174) 
La renovación de los volúmenes de la selección supuso entonces el aumento de una selección de más de 100 libros en los que Samper puso su mirada y adaptó textos desde la perspectiva "literaria". A este respecto, el editor de la Selección precisó lo siguiente:

[...] Para otra edición, que esté lista más o menos dentro de cinco o seis años me haría falta contar con la colaboración de todos los eruditos de buena voluntad. [...]

La cooperación que solicito de mis amigos se reduce a los siguientes puntos:

1- A que se sirvan de anotarme los errores de imprenta que hayan observado en las ediciones anteriores, que, en realidad, vienen siendo una misma, aunque parezcan tres distintas [...]

2- A que se sirvan de anotarme con toda franqueza, honradez y patriotismo, cuáles son los autores que sobran, según los críticos, pero que nadie me ha puntualizado, y cuáles son los que hacen falta: pero en este segundo caso habría que indicar los títulos de las obras aconsejables (Samper Ortega, s.f.: 1 folio).

Con esta cuarta edición, la selección alcanzó cerca de 120 volúmenes que, según la perspectiva de un colectivo que venía asesorando a Samper desde la publicación de la selección, buscaba ordenar y segmentar obras y autores importantes. Posiblemente algunos vieron con perjuicio la idea de agrupar varios escritores en un solo volumen, lo que llevó a que Samper se inclinara por determinar que, por ejemplo, Bolívar tuviera su propio libro. El mayor ajuste que se hacía a la selección era la "tonificación", en palabras de Samper, y quizás esta tendencia o reclamo común fue un antecedente de la aparición de posteriores colecciones, como la Biblioteca Popular de Cultura Colombiana, creada entre 1941 y 1942 (Marín Colorado, 2017).

\section{Propiedad literaria}

La selección de textos ideada por Samper quizás no comenzó con una denominación específica que el compilador asignara desde sus inicios, en 1928. Casi siempre en la correspondencia más antigua que se conoce sobre su iniciativa, Daniel Samper se refería a una "colección de autores colombianos", pero no anticipaba sobre el nombre que esta llevaría. Por ello, posiblemente en 1930 la Editorial Minerva propuso el rótulo "Selección Samper Ortega de Literatura Colombiana" puesto que, como lo indicaba Samper, la empresa

aspiraba a proteger sus intereses, y para ello necesitaba dar a ese conjunto un nombre que lo pusiera a cubierto de plagios y de sisas más o menos hábiles, pues en ello sí que somos expertos en América, donde la propiedad literaria no se respeta (Samper Ortega, 1937a: 10-11).

Lo interesante es que antes de 1937 no hay registro de propiedad literaria de esta obra, lo cual lleva a pensar que aunque por esos años se crearan otras colecciones similares, ninguna otra podría llamarse "Samper Ortega", y con esto, la Editorial Minerva previó más que todo el extenso tiempo de ejecución que le iba a tomar realizar cada volumen. Así, aunque apareciera una "Selección de literatura colombiana" entre 1930 y 1935, con la pausada impresión y preparación de los pliegos de la primera edición, ya se aseguraba que la de Samper existía y era de su propiedad. Asimismo, sus apellidos servirían para posicionar una colección que posiblemente por sí solo el nombre de la editorial, así como el número de ejemplares o colecciones y número de ediciones, daría al lector o comprador un contexto de su procedencia. Aunque fuera criticado como obra de un solo sujeto, situarse en las portadas y los 
lomos de las distintas ediciones reafirmaría su condición de editor de una colección editorial, a la manera, en su momento, de Jorge Roa (Biblioteca Popular) o Eduardo Santos (Lecturas Populares).

La institución que se encargaba del registro de propiedad literaria durante esos primeros años del siglo XX era el Ministerio de Instrucción Pública, que luego se transformó en el Ministerio de Educación Nacional; a este última se dirigió Samper el 11 de agosto de 1937, junto con una serie de requisitos que por la Ley 32 de 1886 y el Decreto 665 de 26 de noviembre de 1886 se exigían para la inscripción de obras. Entre estos se solicitaba tres ejemplares de la obra, tres sellos de papel (para acompañar al memorial) y las estampillas por valor de \$ 5.00 . El proceso consistía en iniciar la solicitud ante el secretario del Ministerio, quien certificaba y adelantaba el procedimiento, e indicaba al autor las respectivas firmas y la autorización para que publicara dicha petición en el Diario Oficial (Ministerio de Educación Nacional, 1937).

\section{Conclusiones}

Pensar una serie de textos de carácter literario que tratan y son de la autoría de escritores colombianos encarna un conjunto de acontecimientos y herramientas provenientes de un pasado caracterizado por ciertas formas y tradiciones editoriales. Cualquiera que sea el caso por abordar, la historia de la edición y del libro en Colombia deben considerar que no existe la noción de "proyecto", "empresa" o "iniciativa" sin antes comprender los antecedentes que pudieron o pueden influir en las actividades editoriales de extractar, organizar, seleccionar, volver a reestructurar, en últimas, reeditar y divulgar bajo otras discursividades. Gran parte de los antecedentes revisados fueron indispensables para "voltear la mirada" a la producción editorial desde el siglo XIX, para replantear nuevas formas textuales y editoriales que lograran acercar a nuevos lectores, quienes no tenían acceso o conocimiento de autores y obras, e incluso, de discursos académicos y culturales como la idea de pensar en la "literatura colombiana" a partir de unos géneros y categorías.

Bajo estas consideraciones, la Selección Samper Ortega de Literatura Colombiana encontró, durante los años de la vida editorial de volúmenes y prospectos de colecciones y bibliotecas, una forma de existencia que el contexto y su compilador determinaron como acertada para evidenciar qué era literatura colombiana y de qué obras fundamentales se componía. El papel ejercido por Daniel Samper Ortega en varias publicaciones bogotanas, en los años veinte y principios de los treinta del siglo $\mathrm{XX}$, muestra las diversas relaciones autorales, editoriales y comerciales que ejerció como epicentro de ciertas dinámicas que solo un individuo podía controlar. Desde la obtención y tratamiento de un original conservado en su biblioteca personal, hasta la negociación del sostenimiento de revistas le otorgaron a Samper una experiencia que fue crucial para definir su labor como compilador de obras colombianas realizadas hasta su presente. Se debe precisar la distinción de "realizadas" en vez de "publicadas", pues gran parte de los textos pertenecientes a la Selección Samper Ortega fueron encargados de forma inédita, como un compromiso que el escritor asumía con el compilador, pero asimismo con el firme propósito de figurar entre los "selectos", los "escogidos", para representar la literatura colombiana.

Las cartas enviadas y recibidas trajeron consigo múltiples detalles que confirmaron el contenido definitivo de una biografía o la autoría de un texto. Más de 300 fuentes de distinto tipo de origen (entre revistas, periódicos, libros, recortes, transcripciones a mano y mecanografiadas) evidencian una larga lectura de nueve años que no se conformó con lo obtenido, sino que tras este ejercicio interrogó a sus autores (los que 
estaban vivos) sobre su pertinencia, actualidad y autorizaciones (aunque no siempre se respetó las interdependencias entre autores, amigos, colegas y la propiedad literaria).

Finalmente, las actividades editoriales de Daniel Samper Ortega no se limitaron a componer originales mecanografiados para ser entregados a la editorial que se encargaría de imprimirlos y distribuirlos. Su relación cercana con los gerentes y propietarios de la Editorial Minerva como Pedro Ignacio Escobar y Juan Antonio Rodríguez lo ubicaron en cargos administrativos que buscaron acercar más las relaciones entre compilador y editores. Este debate sobre la denominación de compilador (por ley el autor de un compendio de obras extractadas) y el editor (relativo a la empresa editorial o quien pertenece o administra una editorial) es fundamental para entender los sitios, los lugares y las nociones referenciales entre las partes de un complejo proceso editorial. Según estas consideraciones, el editor en Colombia, para el periodo de estudio, es quien posee el capital de inversión para subvencionar proyectos editoriales bajo las pautas y las guías de un taller impresor que se encarga de la idea material y formal de los libros, como así lo dejó ver Samper en partes de su correspondencia refiriéndose a Pedro Escobar en representación de la Editorial Minerva. Sin embargo, parece que convivieron dos percepciones: se insiste en la idea de Chartier de que el editor es aquel que se encarga de la elección de textos, al negocio de los libros y la búsqueda y encuentro con un público de lectores (Chartier, 1999), "una serie de actos destinados a salvaguardar el patrimonio escrito de la humanidad", mediante "objetos durables, multiplicados y difundidos" (Chartier, 2000: 181). 


\section{Q Referencias bibliográficas}

"Adams, Thomas R. y Nicolas Barker. 2001. A new model for the study of the book. En Nicolas Barker, ed. A Potencie of Life: Books in Society. Londres: British Library, Oak Knoll Press. pp. 5-43

"Chartier, Roger. 1999. Cultura escrita, literatura e historia. Conversaciones con Roger Chartier. México: Fondo de Cultura Económica.

»Chartier, Roger. 200o. Las revoluciones de la cultura escrita. Diálogos e intervenciones. Barcelona: Gedisa.

"Darnton, Robert. 1982. What is the history of books? En Daedalus. Vol. 111, no.3, 65-83.

» Hernández de Alba, Guillermo. 1961. Daniel Samper Ortega: homenaje a su obra. En Boletín Cultural y Bibliográfico. Vol. 4, no. 3, 175-178.

"López de Mesa, Luis. 1927. Bibliotecas aldeanas. En Universidad. No. 44. (27 de agosto)

» Marín Colorado, Paula Andrea. 2017. La colección Biblioteca Popular de Cultura Colombiana 1942-1952. Ampliación del público lector y fortalecimiento del campo editorial colombianos. En Información, Cultura y Sociedad. No. 36, 6582. <http://revistascientificas.filo.uba.ar/index.php/ICS/article/view/2886>

" Ministerio de Educación Nacional. 1935. Contrato sobre publicación de 2,000 colecciones de la Selección Samper Ortega Bogotá. En Diario Oficial. Año LXXI, no. 22903, viernes 7 de junio de 1935, 531-532.

» Ministerio de Educación Nacional. 1937. Expediente. Sección 2.a Selección Samper Ortega de Literatura Colombiana. En CO.AGN.SAA-II.22.14.202, Paquete 159, Negocios Generales. Propiedad Literaria, f. 303, 12 de agosto de 1937. Bogotá: Archivo General de la Nación AGN.

»Ministerio de Industrias de Colombia 1930. Directorio comercial e industrial del país. Bogotá: Imprenta Nacional de Colombia.

» Osorio, Luis E. 1944. Daniel Samper Ortega, por Luis Enrique Osorio. En El Teatro. Vol. 1, no. 4, 1-9.

"Otero Muñoz, Gustavo. 1931. [Carta para Daniel Samper Ortega, Bucaramanga, 1 diciembre de 1931]. En Archivo Daniel Samper Ortega, carpeta sin nombre, archivador 3. Bogotá: Biblioteca Los Fundadores, Gimnasio Moderno.

»Otero Muñoz, Gustavo. 1932a. [Carta para Daniel Samper Ortega, Bucaramanga, 28 de enero de 1932]. En Archivo Daniel Samper Ortega, carpeta "Otero Muñoz Gustavo". Bogotá: Biblioteca Los Fundadores, Gimnasio Moderno.

"Otero Muñoz, Gustavo. 1932b. [Carta para Daniel Samper Ortega, Bucaramanga, 12 de mayo de 1932]. En Archivo Daniel Samper Ortega, carpeta “Otero Muñoz Gustavo", archivador 1. Bogotá: Biblioteca Los Fundadores, Gimnasio Moderno.

»Otero Muñoz, Gustavo. 1937. Historia del Periodismo en Colombia. Bogotá: Editorial Minerva S.A. (Selección Samper Ortega de Literatura colombiana, sección 7a., Ensayos, no. 61)

"Rincón, Carlos. 2010. Canon y clásicos literarios en la década de 1930. En Carlos Rincón, Sarah de Mojica y Liliana Gómez, eds. Entre el olvido y el recuerdo. 
Íconos, lugares de memoria y cánones de la historia y la literatura en Colombia. Bogotá: Editorial Pontificia Universidad Javeriana. p. 419-477

» Rubio Marroquín, Vicente. 1933. [Carta para Daniel Samper Ortega, Bogotá, 19 de enero de 1933]. En Archivo Daniel Samper Ortega, carpeta "Editorial Minerva". Bogotá: Biblioteca Los Fundadores, Gimnasio Moderno.

» Samper Ortega, Daniel. 1928. Programa de castellano y literatura. En Archivo Daniel Samper Ortega, carpeta Gimnasio Moderno. Bogotá: Biblioteca Los Fundadores, Gimnasio Moderno.

"Samper Ortega, Daniel. 1934. [Carta para Camilo Carrizosa, 25 de abril de 1934]. En Archivo Daniel Samper Ortega, ADSO, carpeta "Varios C". Bogotá: Biblioteca Los Fundadores, Gimnasio Moderno.

»Samper Ortega, Daniel. 1935. [Carta para Francisco Urrutia Olano, Bogotá, 15 de enero de 1935]. En Biblioteca Nacional de Colombia, Archivo Histórico, AHBNC, tomo 111, Senderos, enero a abril.

» Samper Ortega, Daniel. 1937a. Selección Samper Ortega de Literatura Colombiana. Índices. Bogotá: Editorial Minerva S. A.

» Samper Ortega, Daniel. 1937b. [Carta para Arturo Zapata, Bogotá, 5 de julio de 1937]. En Archivo Daniel Samper Ortega, carpeta “Editorial Minerva”. Bogotá: Biblioteca Los Fundadores, Gimnasio Moderno.

»Samper Ortega, Daniel. 1940. La Biblioteca Nacional y su exposición del libro. Bogotá: $A B C$.

»Samper Ortega, Daniel. dir. 1931. Obras escogidas de don José María Vergara y Vergara Bogotá: Editorial Minerva S. A. 4 vols.

» Samper Ortega, Daniel. s.f. Manuscrito mecanografiado sobre el plan de la cuarta edición de la Selección Samper Ortega. En Archivo Daniel Samper Ortega, ADSO, carpeta "Selección Samper Ortega 4. Edición", 1 folio. Bogotá: Biblioteca Los Fundadores, Gimnasio Moderno.

"Samper Ortega, Daniel. s.f. Proyecto de contrato. En Archivo Daniel Samper Ortega, ADSO, carpeta “Contratos literarios”, 4 folios. Bogotá: Biblioteca Los Fundadores, Gimnasio Moderno.

"Silva, Renán. 2012. República Liberal, intelectuales y cultura popular. Medellín: La Carreta.

»Silva, Renán. 2004. Relación de imprentas y tipografías en Colombia, 1935. En Revista Sociedad y Economía. Vol. 6, 159-171.

»Suescún, Eduardo. 1937. [Carta para Daniel Samper Ortega, Bogotá, 2 de noviembre de 1937]. En Biblioteca Nacional de Colombia, Archivo Histórico, AHBNC, tomo 393, ASUNTOS VARIOS A-C.

»Vanderhuck, Felipe. 2012. La literatura como oficio: José Antonio Osorio Lizarazo 1930-1946. Medellín: La Carreta Editores.

»Vasco Acosta, Juliana. 2018. Sociedades literarias en Colombia en la segunda mitad del siglo XX: proyectos de edición y difusión. En Diana P. Guzmán Méndez, Paula Marín Colorado, Juan D. Murillo Sandoval y Miguel Ángel Pineda Cupa, eds., Lectores, editores y cultura impresa en Colombia. Siglos xvi-xxi. Bogotá: Universidad Jorge Tadeo Lozano, Cerlalc. p. 249-276 
Secciones literarias, títulos y autores de la Selección Samper Ortega de Literatura Colombiana

\begin{tabular}{|c|c|c|c|}
\hline Sección & $\mathrm{N}^{\circ}$ & Título & Autores \\
\hline \multirow[t]{10}{*}{ Prosa literaria } & 1 & Del uso en sus relaciones con el lenguaje & Miguel Antonio Caro \\
\hline & 2 & El castellano en América & Rufino José Cuervo \\
\hline & 3 & Escritos & Marco Fidel Suárez \\
\hline & 4 & Retórica y poética & José Manuel Marroquín \\
\hline & 5 & De la novela & Diego Rafael de Guzmán \\
\hline & 6 & Oraciones & Rafael María Carrasquilla \\
\hline & 7 & Discursos & Guillermo Valencia \\
\hline & 8 & Crítica literaria & Antonio Gómez Restrepo \\
\hline & 9 & Idola Fori & Carlos Arturo Torres \\
\hline & 10 & Prosas & Armando Solano \\
\hline \multirow[t]{10}{*}{$\begin{array}{l}\text { Cuento y } \\
\text { novela }\end{array}$} & 11 & Varias cuentistas colombianas & $\begin{array}{l}\text { Josefa Acevedo de Gómez } \\
\text { Mercedes Párraga de Quijano } \\
\text { Waldina Dávila de Ponce } \\
\text { Soledad Acosta de Samper } \\
\text { Eufemia Cabrera de Borda } \\
\text { Priscila Herrera de Núñez } \\
\text { Herminia Gómez Jaime de Abadía } \\
\text { Concepción Jiménez de Araújo } \\
\text { Ester Flórez Álvarez de Sánchez Ramírez } \\
\text { Julia Jimeno de Pertuz } \\
\text { Sofía Ospina de Navarro } \\
\text { Blanca Isaza de Jaramillo Meza } \\
\text { María Cárdenas Roa Luz Stella } \\
\text { María Castello } \\
\text { Cleonice Nannetti Eco Nelly }\end{array}$ \\
\hline & 12 & Novelas & Tomás Carrasquilla \\
\hline & 13 & Inocencia & Francisco P. de Rendón \\
\hline & 14 & Tránsito & Luis Segundo de Silvestre \\
\hline & 15 & Cuentos & José María y Evaristo Rivas Groot \\
\hline & 16 & Reminiscencias tudescas & Santiago Pérez Triana \\
\hline & 17 & Tres cuentistas jóvenes & $\begin{array}{l}\text { Manuel García Herreros, J. A. Osorio Lizarazo y E. } \\
\text { Arias Suárez }\end{array}$ \\
\hline & 18 & La obsesión & Daniel Samper Ortega \\
\hline & 19 & Varios cuentistas antioqueños & $\begin{array}{l}\text { Samuel Velásquez } \\
\text { Jesús del Corral } \\
\text { Pedro Uribe Gómez } \\
\text { Alfonso Castro }\end{array}$ \\
\hline & 20 & Otros cuentistas & $\begin{array}{l}\text { Jorge Isaacs } \\
\text { Efe Gómez } \\
\text { Gregorio Castañeda Aragón } \\
\text { Julio Vives Guerra } \\
\text { Luis Tablanca } \\
\text { Adel López Gómez }\end{array}$ \\
\hline
\end{tabular}




\begin{tabular}{|c|c|c|c|}
\hline \multirow{10}{*}{$\begin{array}{l}\text { Cuadros de } \\
\text { costumbres }\end{array}$} & 21 & Cuadros de costumbres & José Manuel Groot \\
\hline & 22 & $\begin{array}{l}\text { Cuadros de costumbres de Rafael Eliseo } \\
\text { Santander, Juan Francisco Ortiz y José } \\
\text { Caicedo Rojas }\end{array}$ & $\begin{array}{l}\text { Rafael Eliseo Santander } \\
\text { Juan Francisco Ortiz } \\
\text { José Caicedo Rojas }\end{array}$ \\
\hline & 23 & $\begin{array}{l}\text { Una ronda de don Ventura Ahumada y } \\
\text { otros cuadros }\end{array}$ & Eugenio Díaz \\
\hline & 24 & Las tres tazas y otros cuadros & José María Vergara y Vergara \\
\hline & 25 & Un domingo en casa y otros cuadros & Ricardo Silva \\
\hline & 26 & Cuadros de costumbres & José David Guarín \\
\hline & 27 & La niña Agueda y otros cuadros & Manuel Pombo \\
\hline & 28 & Memorias de un colegial & Luciano Rivera Garrido \\
\hline & 29 & Mi compadre Facundo y otros cuadros & Emiro Kastos \\
\hline & 30 & $\begin{array}{l}\text { Un sábado en mi parroquia y otros } \\
\text { cuadros }\end{array}$ & Femín de Pimentel y Vargas \\
\hline \multirow{10}{*}{$\begin{array}{l}\text { Historia y } \\
\text { leyendas }\end{array}$} & 31 & Historia de la Nueva Granada & José Manuel Restrepo \\
\hline & 32 & Memorias de un abanderado & José María Espinosa \\
\hline & 33 & La batalla del Santuario & Joaquín Posada Gutiérrez \\
\hline & 34 & De la vida de antaño & José María Cordovez Moure \\
\hline & 35 & Boyacá & Cayo Leonidas Peñuela \\
\hline & 36 & El Dorado & Eduardo Posada \\
\hline & 37 & Mosquera, y otros estudios & Raimundo Rivas \\
\hline & 38 & $\begin{array}{l}\text { Leyendas de José María Quijano Otero, } \\
\text { Luis Capella Toledo, Camilo S. Delgado y } \\
\text { Manuel José Forero }\end{array}$ & $\begin{array}{l}\text { José María Quijano Otero } \\
\text { Luis Capella Toledo } \\
\text { Camilo S. Delgado } \\
\text { Manuel José Forero }\end{array}$ \\
\hline & 39 & Leyendas & Enrique Otero D’Costa \\
\hline & 40 & Los Mochuelos & Enrique de Narváez \\
\hline \multirow{10}{*}{$\begin{array}{l}\text { Ciencias y } \\
\text { educación }\end{array}$} & 41 & Viajes Viajes al corazón de Barnuevo & Francisco José de Caldas \\
\hline & 42 & La medicina en Antioquia & Manuel Uribe Ángel \\
\hline & 43 & Escritos & Miguel Samper \\
\hline & 44 & Cuadros de la naturaleza & Joaquín Antonio Uribe \\
\hline & 45 & Antigüedades neogranadinas & Ezequiel Uricoechea \\
\hline & 46 & Estudios & Salvador Camacho Roldán \\
\hline & 47 & Botánica indígena & Florentino Vezga \\
\hline & 48 & La Expedición Botánica & Florentino Vezga \\
\hline & 49 & $\begin{array}{l}\text { La sociedad contemporánea y otros } \\
\text { escritos }\end{array}$ & Luis Eduardo López de Mesa \\
\hline & 50 & $\begin{array}{l}\text { Sobre el problema de la educación } \\
\text { nacional }\end{array}$ & Agustín Nieto Caballero \\
\hline
\end{tabular}




\begin{tabular}{|c|c|c|c|}
\hline \multirow[t]{10}{*}{ Ensayos } & 51 & $\begin{array}{l}\text { Las ciencias, las letras y las bellas artes } \\
\text { en Colombia }\end{array}$ & Sergio Arboleda \\
\hline & 52 & $\begin{array}{l}\text { Semblanzas Diego Fallon y José Manuel } \\
\text { Marroquín }\end{array}$ & José Joaquín Casas \\
\hline & 53 & Los contertulios de la Gruta Simbólica & Luis María Mora \\
\hline & 54 & Eruditos antioqueños & $\begin{array}{l}\text { Tomás O. Eastman } \\
\text { Laureano García Ortiz } \\
\text { Baldomero Sanín Cano }\end{array}$ \\
\hline & 55 & $\begin{array}{l}\text { El doctor José Félix de Restrepo y su } \\
\text { época }\end{array}$ & Mariano Ospina \\
\hline & 56 & Crítica & Fernando de la Vega \\
\hline & 57 & Críticas & Luis Eduardo Nieto Caballero \\
\hline & 58 & La sabana de Bogotá & Tomás Rueda Vargas \\
\hline & 59 & Biografía de Gregorio Vásquez & Roberto Pizano \\
\hline & 60 & Prehistoria colombiana & Juan C. Hernández \\
\hline \multirow[t]{10}{*}{ Periodismo } & 61 & Historia del periodismo en Colombia & Gustavo Otero Muñoz \\
\hline & 62 & Periodistas de los albores de la República & $\begin{array}{l}\text { Jorge Tadeo Lozano } \\
\text { Fray Diego Francisco Padilla } \\
\text { José María Salazar } \\
\text { Juan García del Río }\end{array}$ \\
\hline & 63 & Editoriales del Neo-Granadino & Manuel Ancízar \\
\hline & 64 & Periodistas liberales del siglo xix & $\begin{array}{l}\text { Felipe Pérez } \\
\text { Santiago Pérez } \\
\text { Felipe Zapata } \\
\text { Fidel Cano } \\
\end{array}$ \\
\hline & 65 & $\begin{array}{l}\text { Los mejores artículos políticos de Rafael } \\
\text { Núñez }\end{array}$ & Rafael Núñez \\
\hline & 66 & Prosa política & Carlos Martínez Silva \\
\hline & 67 & $\begin{array}{l}\text { Artículos varios de José y Guillermo } \\
\text { Camacho Carrizosa }\end{array}$ & $\begin{array}{l}\text { José Camacho Carrizosa } \\
\text { Guillermo Camacho Carrizosa }\end{array}$ \\
\hline & 68 & Semblanzas y editoriales & Luis Cano \\
\hline & 69 & $\begin{array}{l}\text { Periodismo Eduardo, Enrique y Gustavo } \\
\text { Santos }\end{array}$ & $\begin{array}{l}\text { Eduardo Santos } \\
\text { Enrique Santos } \\
\text { Gustavo Santos }\end{array}$ \\
\hline & 70 & Antología de periodistas & Varios autores \\
\hline
\end{tabular}




\begin{tabular}{|c|c|c|c|}
\hline \multirow[t]{10}{*}{ Elocuencia } & 71 & $\begin{array}{l}\text { Antonio Nariño, Francisco de Paula } \\
\text { Santander y Julio Arboleda }\end{array}$ & $\begin{array}{l}\text { Antonio Nariño } \\
\text { Francisco de Paula Santander } \\
\text { Julio Arboleda }\end{array}$ \\
\hline & 72 & $\begin{array}{l}\text { Bolívar, Camilo Torres y Francisco } \\
\text { Antonio Zea }\end{array}$ & $\begin{array}{l}\text { Simón Bolívar } \\
\text { Camilo Torres } \\
\text { Franciso Antonio Zea } \\
\end{array}$ \\
\hline & 73 & Oradores liberales & $\begin{array}{l}\text { José María Rojas Garrido } \\
\text { Nicolás Esguerra } \\
\text { José Ignacio Escobar } \\
\text { Rafael Uribe Uribe } \\
\text { Antonio José Restrepo } \\
\text { Enrique Olaya Herrera } \\
\end{array}$ \\
\hline & 74 & Oradores conservadores & $\begin{array}{l}\text { José Vicente Concha } \\
\text { Hernando Holguín y Caro } \\
\text { Emilio Ferrero } \\
\text { Eduardo Zuleta } \\
\text { Alfonso Robledo } \\
\end{array}$ \\
\hline & 75 & Sermones & Manuel José Mosquera \\
\hline & 76 & Oradores sagrados de fin de siglo & $\begin{array}{l}\text { Carlos Cortés Lee } \\
\text { Francisco Javier Zaldúa } \\
\text { Juan Buenaventura Ortiz }\end{array}$ \\
\hline & 77 & Sermones y discursos & José Vicente Castro Silva \\
\hline & 78 & $\begin{array}{l}\text { Selección oratoria de Juan Crisóstomo } \\
\text { García }\end{array}$ & Juan Crisóstomo García \\
\hline & 79 & $\begin{array}{l}\text { Oradores sagrados de la generación del } \\
\text { centenario }\end{array}$ & \begin{tabular}{|l} 
José Manuel Marroquín \\
José Alejandro Bermúdez \\
R. P. Félix Restrepo, S. J. \\
\end{tabular} \\
\hline & 80 & Los jóvenes oradores sagrados & $\begin{array}{l}\text { Jorge Murcia Riaño } \\
\text { Álvaro Sánchez } \\
\text { José Manuel Díaz } \\
\text { José Eusebio Ricaurte }\end{array}$ \\
\hline \multirow[t]{10}{*}{ Poesía } & 81 & Los poetas. Flores de varia poesía & Varios autores \\
\hline & 82 & Los poetas. Del dolor y de la muerte & Varios autores \\
\hline & 83 & Los poetas. Del amor y de la mujer & Varios autores \\
\hline & 84 & Los poetas. De la naturaleza & Varios autores \\
\hline & 85 & Los poetas. Ingenios festivos & Varios autores \\
\hline & 86 & Los poetas del amor divino & Varios autores \\
\hline & 87 & Los poetas. De la Patria. & Varios autores \\
\hline & 88 & Los poetas fábulas y cuentos & Varios autores \\
\hline & 89 & Las mejores poetistas colombianas & Varias autoras \\
\hline & 90 & Los poetas. De otras tierras & Varios autores \\
\hline
\end{tabular}




\begin{tabular}{|l|l|l|l|}
\hline Teatro & 91 & Las convulsiones y Doraminta & Luis Vargas Tejada \\
\cline { 2 - 4 } & 92 & Atala y Guatimoc Tragedias en verso & José Fernández Madrid \\
\cline { 2 - 4 } & 93 & $\begin{array}{l}\text { Piezas de teatro de Carlos Sáenz } \\
\text { Echeverría y José Manuel Lleras }\end{array}$ & $\begin{array}{l}\text { Carlos Sáenz Echeverría } \\
\text { José Manuel Lleras }\end{array}$ \\
\cline { 2 - 5 } 94 & $\begin{array}{l}\text { Un alcalde a la antigua y dos primos a } \\
\text { la moderna Comedia de costumbres } \\
\text { nacionales }\end{array}$ & José María Samper \\
\cline { 2 - 5 } & 95 & Lo irremediable & Lorenzo Marroquín y J. M. Rivas Groot \\
\cline { 2 - 4 } & 96 & Traducciones teatrales & Roberto Mc. Douall \\
\cline { 2 - 4 } & 97 & El tesoro & Ángel María Céspedes \\
\cline { 2 - 4 } & 98 & Víboras sociales y fuego extraño & Antonio Álvarez Lleras \\
\cline { 2 - 5 } & 99 & El iluminado & Luis Enrique Osorio \\
\cline { 2 - 4 } & 100 & El regreso de Eva & Daniel Samper Ortega, compilador-editor \\
\hline
\end{tabular}


